\title{
COMPARISON OF TOPICAL AND ORAL ACYCLOVIR IN EARLY HERPES ZOSTER OPHTHALMICUS
}

\author{
C. NEOH ${ }^{1}$, S. P. HARDING ${ }^{1}$, D. SAUNDERS ${ }^{2}$, S. WALLIS ${ }^{2}$, A. B. TULLO ${ }^{2}$, A. NYLANDER ${ }^{3}$ \\ and M. E. NELSON ${ }^{3}$ \\ Liverpool, Manchester and Sheffield
}

\begin{abstract}
SUMMARY
Poor systemic absorption has limited the efficacy of early oral acyclovir in herpes zoster ophthalmicus (HZO). Aqueous humour levels are substantially higher if the drug is administered topically to the eye. A multicentre open randomised study was performed to compare the ocular prophylactic effects of topical and oral acyclovir. Fifty-seven patients with $\mathrm{HZO}$ within $\mathbf{7 2}$ hours of the onset of rash received either topical acyclovir ointment or $800 \mathrm{mg}$ oral acyclovir, both 5 times daily for $\mathbf{7}$ days, and were followed for 12 months. Patients receiving ointment were significantly more likely to have ocular complications $(p<0.02)$ and anterior uveitis was significantly more frequent $(p<0.01)$ and severe $(p<0.01)$. Corneal hypoaesthesia was significantly more frequently $(p<0.05)$ and severe $(p<0.02)$ at 1 month. From 2 weeks patients receiving ointment were more likely to have pain and at all times their pain was more severe, but these differences were not statistically significant. In spite of its apparently better penetration topical acyclovir appears to have no prophylactic value in the management of early HZO.
\end{abstract}

Herpes zoster is the commonest disease of the nervous system. Prevalence increases with age and it has been estimated that each individual has a $50 \%$ risk of being affected by age 85 years and a $1 \%$ chance of being affected twice.' Of affected cases $10-17 \%$ are ophthalmic, and this is the second commonest site after thoracic dermatomes. ${ }^{2.3}$

Ocular complications at some time after the onset of rash occur with a frequency of around 50\% in herpes zoster ophthalmicus (HZO), with activity persisting for 6 months or more in up to $28 \%$ of initially affected eyes. ${ }^{4}$ Incidence and severity of ocular complications are not related to age, sex or severity of rash, but involvement of the external division of the nasociliary nerve is significantly associated with the development of ocular complications. Complications in $\mathrm{HZO}$ are varied, ${ }^{4-8}$ with anterior uveitis being the commonest followed by varieties of kera-

From: ' St Paul's Eye Unit, Royal Liverpool University Hospital, Liverpool, UK; ${ }^{2}$ Manchester Royal Eye Hospital, Manchester, UK; ${ }^{3}$ Roy al Hallamshire Hospital, Sheffield, UK.

Correspondence to: Mr S. P. Harding, St Paul's Eye Unit, Royal Liverpool University Hospital, Prescot Street, Liverpool L7 8XP, UK. titis. Onset of acute ocular complications ranges between 7 and 28 days. Up to $93 \%$ of patients with HZO experience acute pain. ${ }^{4}$ Chronic pain occurs in up to $34 \%,{ }^{1,2,4,9,10}$ becoming more frequent with age and rising to $71 \%$ in those aged 80 years and over. ${ }^{4}$

Management of HZO remains controversial. Recent attention has centred on the role of antivirals and in particular acyclovir in management and prophylaxis. There is also a role for topical steroids but the precise relationship between these two therapeutic options remains unclear. ${ }^{11,12}$ Two studies have reported prophylactic effects in the eye of oral acyclovir in HZO provided it is commenced within 72 hours of the onset of rash. ${ }^{13,14}$ Results were somewhat conflicting, with one study showing an early ${ }^{13}$ and one a late effect. ${ }^{14} \mathrm{~A}$ retrospective casecontrol investigation failed to detect a significant therapeutic effect. ${ }^{15}$ Double-masked placebo-controlled studies on the effect of acyclovir on pain in $\mathrm{HZO}^{13,14}$ and in nonophthalmic herpes zoster ${ }^{16-18}$ have also produced conflicting results. All have shown a prophylactic effect on pain but this has either been early or late. Because of these studies the use of early oral acyclovir has become widespread, although several ophthalmologists do not use oral acyclovir routinely for $\mathrm{HZO}$ because of the relatively high cost and doubts about efficacy.

Oral acyclovir is only partially absorbed, with plasma levels which plateau at doses above $800 \mathrm{mg}^{19}$ and are only slightly higher than the mean effective dose $\left(E D_{50}\right)$ for most strains of varicella zoster virus..$^{20,21}$ It seems likely that the benefits of oral acyclovir are limited by poor systemic absorption. Aqueous humour levels are substantially higher if the drug is administered topically to the eye $^{22}$ and this formulation may offer better ocular efficacy than the oral drug as well as being considerably cheaper. This paper reports on a multicentre randomised open study to compare the prophylactic effects of topical and oral acyclovir commenced early in the disease.

\section{PATIENTS AND METHODS}

Patients presenting with $\mathrm{HZO}$ with rash of less than 72 hours duration were recruited at three centres: St Paul's

Eye (1994) 8, 688-691 C 1994 Royal College of Ophthalmologists 
Table I. Frequency of ocular complications

\begin{tabular}{|c|c|c|c|c|c|c|c|c|c|c|c|c|}
\hline & \multicolumn{2}{|c|}{2 weeks } & \multicolumn{2}{|c|}{1 month } & \multicolumn{2}{|c|}{3 months } & \multicolumn{2}{|c|}{6 months } & \multicolumn{2}{|c|}{12 months } & \multicolumn{2}{|c|}{ Cumulative } \\
\hline & $n$ & $\%$ & $n$ & $\%$ & $n$ & $\%$ & $n$ & $\%$ & $n$ & $\%$ & $n$ & $\%$ \\
\hline Ointment & $13 / 25$ & 52.0 & $12 / 25$ & 48.0 & $6 / 22$ & 27.3 & $2 / 18$ & 11.1 & $4 / 9$ & 44.4 & $17 / 25$ & 68.0 \\
\hline Tablets & $9 / 32$ & 28.1 & $7 / 29$ & 24.1 & $1 / 23$ & 4.3 & $2 / 24$ & 8.3 & $0 / 15$ & 0.0 & $11 / 32$ & 34.4 \\
\hline $\begin{array}{l}\chi^{2} \\
p\end{array}$ & \multicolumn{2}{|c|}{3.376} & \multicolumn{2}{|c|}{3.352} & \multicolumn{2}{|c|}{4.499} & \multicolumn{2}{|c|}{0.092} & \multicolumn{2}{|c|}{8.000} & 6.349 & \\
\hline
\end{tabular}

Eye Hospital, Liverpool; Manchester Royal Eye Hospital; and Royal Hallamshire Hospital, Sheffield. After giving their informed written consent patients were randomised at presentation to receive either topical acyclovir ointment 5 times daily for 7 days or $800 \mathrm{mg}$ oral acyclovir 5 times daily for 7 days.

Ocular complications were defined as any ocular disease secondary to HZO but excluding mild surface ocular complications such as conjunctivitis and mild punctate keratopathy. Patients with established ocular complications at presentation were excluded. Other exclusion criteria were: compromised immune status, topical or systemic antiviral therapy at presentation, pregnancy or lactation, renal failure, moderate or severe hypertension, diabetes mellitus, previous relevant eye disease including surgically treated cataract and glaucoma, chronic uveitis and keratitis.

Patients were assessed at the following intervals after commencement of treatment: 3-5 days (first half of treatment), 7-10 days (second half of treatment), 2 weeks (immediate post-treatment), and 1, 2, 3,6 and 12 months. Additional visits were made as determined by the nature of any ocular complications.

Chronicity was defined as the presence of active ocular complications 6 months after the onset of rash when all ocular treatment had been withdrawn for a minimum of 2 weeks.

Variables measured were pain, anterior uveitis, sclerokeratitis, scleritis, corneal involvement including disciform keratitis and corneal sensation. Severities were recorded on an ordinal scale from 0 to 3 , with 0 representing absent. The highest score for flare, cells, keratic precipitates and hypopyon was taken as the total uveitis score for any particular visit. Corneal sensation was tested by comparison of a light touch with a cotton wool strand against the normal fellow eye and recorded as normal, reduced or absent. Pain was measured in response to the standard question, 'On average, how bad has the pain been in the last 24 hours?'; it was scored on a visual analogue scale set vertically for $100 \mathrm{~mm}$.
If ocular complications developed subsequently they were treated with topical acyclovir and steroids were withheld except in severe or deteriorating disease (severe hypopyon uveitis, posterior scleritis, orbital apex syndrome). ${ }^{14}$ Cyclopentolate $1 \%$ was used as necessary. Glaucoma was controlled with topical beta-blockers (or dipivefrine in known asthmatics) if the intraocular pressure rose above $30 \mathrm{mmHg}$. Post-herpetic pain was treated with sodium valproate and/or low-dose amitriptyline as necessary. Analgesics were stopped for 2 weeks at 6 months after the onset of rash to assess the frequency and severity of pain.

It was calculated that a sample size of 150 patients in each arm of the study would be required to detect a $50 \%$ difference in frequency of intraocular involvement with an $80 \%$ power based on an incidence of $30 \%$ with oral acyclovir. ${ }^{14}$ Study duration was estimated at 3 years on the basis of previous recruitment rates. Statistical analysis of frequencies was by one-tailed chi-squared $\left(\chi^{2}\right)$ test and of severities by the Mann-Whitney $U$-test (one-tailed).

\section{RESULTS}

Between March 1990 and May 1992, 70 patients with $\mathrm{HZO}$ were recruited within 72 hours of the onset of rash and commenced on treatment. During the early months recruitment rates were satisfactory but by 1992 the use of oral acyclovir in general practice had become so widespread that the majority of patients presenting with $\mathrm{HZO}$ were already on treatment. Alternatively patients randomised to receive ointment were subsequently prescribed the oral drug by their general practitioner (GP) in spite of regular circular letters and discussion at postgraduate GP training sessions. In May 1992 further recruitment was abandoned at less than the planned sample size and follow-up was completed.

Thirteen patients were excluded from final analysis: 9 were lost to follow-up within 6 weeks and in 4 patients in the ointment group oral acyclovir or steroids were added by other practitioners after recruitment. Data were available for analysis on 30 patients from Liverpool, 21 from

Table II. Frequency of altered corneal sensation (reduced or absent)

\begin{tabular}{|c|c|c|c|c|c|c|c|c|c|c|}
\hline & \multicolumn{2}{|c|}{2 weeks } & \multicolumn{2}{|c|}{1 month } & \multicolumn{2}{|c|}{3 months } & \multicolumn{2}{|c|}{6 months } & \multicolumn{2}{|c|}{ Cumulative } \\
\hline & $n$ & $\%$ & $n$ & $\%$ & $n$ & $\%$ & $n$ & $\%$ & $n$ & $\%$ \\
\hline Tablets & $4 / 18$ & 22.2 & $3 / 20$ & 15.0 & $1 / 18$ & 5.6 & $2 / 14$ & 14.3 & $8 / 21$ & 38.1 \\
\hline $\begin{array}{l}\chi^{2} \\
p\end{array}$ & \multicolumn{2}{|c|}{1.561} & \multicolumn{2}{|c|}{4.859} & & & 0.873 & & & \\
\hline
\end{tabular}


Table III. Frequency of pain

\begin{tabular}{|c|c|c|c|c|c|c|c|c|c|c|c|c|c|c|}
\hline & \multicolumn{2}{|c|}{ Presentation } & \multicolumn{2}{|c|}{1 week } & \multicolumn{2}{|c|}{2 weeks } & \multicolumn{2}{|c|}{1 month } & \multicolumn{2}{|c|}{3 months } & \multicolumn{2}{|c|}{6 months } & \multicolumn{2}{|c|}{12 months } \\
\hline & $n$ & $\%$ & $n$ & $\%$ & $n$ & $\%$ & $n$. & $\%$ & $n$ & $\%$ & $n$ & $\%$ & $n$ & $\%$ \\
\hline Ointment & $20 / 24$ & 83.3 & $19 / 24$ & 79.2 & $18 / 21$ & 85.7 & $17 / 24$ & 70.8 & $7 / 19$ & 36.8 & $7 / 18$ & 38.9 & $1 / 11$ & 9.1 \\
\hline Tablets & $28 / 32$ & 87.5 & $25 / 29$ & 86.2 & $21 / 29$ & 72.4 & $15 / 28$ & 53.6 & $6 / 24$ & 25.0 & $3 / 20$ & 15.0 & $1 / 13$ & 7.7 \\
\hline $\begin{array}{l}\chi^{2} \\
\text { No signific }\end{array}$ & \multicolumn{2}{|c|}{$\begin{array}{r}0.194 \\
\text { difference }\end{array}$} & \multicolumn{2}{|c|}{0.462} & \multicolumn{2}{|c|}{1.256} & \multicolumn{2}{|c|}{1.627} & \multicolumn{2}{|c|}{0.705} & \multicolumn{2}{|c|}{2.788} & \multicolumn{2}{|c|}{0.015} \\
\hline
\end{tabular}

Manchester and 6 from Sheffield (where recruitment problems were especially difficult). These 57 comprised 18 men and 39 women with an age range of 31-88 years and a mean of 64.6 years. Twenty-six patients received topical therapy and 31 received tablets. There was no significant difference between the two groups in age or severity of pain at presentation (median pain scores: $46 \mathrm{~mm}$ ointment, $34 \mathrm{~mm}$ tablets).

Frequencies of ocular involvement during the time bands studied are shown in Table I. At all times during the follow-up period patients receiving tablets were less likely to have intraocular complications than those receiving ointment. This was statistically significant at 3 months and 12 months. Cumulative analysis showed a $68.0 \%$ chance of developing ocular complications at any time after onset in the ointment group and a $34.4 \%$ chance in the tablet group. This difference was significant $\left(\chi^{2}=6.349\right.$, d.f. $=1, p<0.02$ ).

Nineteen patients developed anterior uveitis: 13 in the ointment group and 6 in the tablet group. This difference was significant $\left(\chi^{2}=6.983\right.$, d.f. $\left.=1, p<0.01\right)$. Severities for the ointment group were 7 at level 1,5 at level 2 and 1 at level 3. Severities in the tablet group were 5 at level 1 and 1 at level 2. Severity of anterior uveitis was significantly greater in patients in the ointment group (MannWhitney two-tailed, $p=0.01$ ). Other complications occurred as follows: episcleritis 5 , sclerokeratitis 6 , orbital apex syndrome 1 , cranial nerve palsies 2 , keratitis 4 , glaucoma 1.

Data on corneal sensation were available on 31 patients recruited in Liverpool and 6 in Sheffield. Frequencies of reduced or absent corneal sensation are presented in Table II. Throughout the follow-up period corneal sensation was more likely to be reduced or absent in patients receiving ointment and this was statistically significant at 1 month $(p<0.05)$. Altered corneal sensation tended to recover between 1 and 3 months. Hypoaesthesia was more severe in the ointment group throughout follow-up and this difference was again significant at 1 month $(p=0.01)$.
Frequencies and severity of pain during the time bands studied are shown in Tables III and IV. From 2 weeks patients receiving tablets were less likely to have pain than those receiving ointment and at all times during follow-up their pain was less severe. None of the differences were statistically significant.

\section{DISCUSSION}

Throughout the study there was a trend in favour of patients on oral drug developing less frequent and severe ocular complications. This was statistically significant at 3 and 12 months and also by cumulative analysis. In addition statistically significant benefits of tablets over ointment were detected for anterior uveitis and loss of corneal sensation, for both frequency and severity.

Throughout the study there was a trend in favour of patients on oral drug having less frequent and severe zoster-associated pain. However, the final numbers available for data analysis give our results a statistical power that is lower than projected. Statistical significance was not reached for pain variables at any time; at 6 months the difference in pain severity scores gave a $p$ value of 0.08 and so it is likely that given larger numbers this might have reached significance.

Frequencies of ocular complications in the oral treatment group in our study were $34 \%$ overall and $8 \%$ at 6 months. These are similar to those found in patients studied previously in the north of England in which the incidence of ocular complications was $30 \%$ overall and $5 \%$ at 6 months in patients treated with oral acyclovir. ${ }^{14}$ In this previous study the overall frequency of ocular complications was 53\% in those receiving placebo. The frequency of ocular complications in the ointment group in our study $(68 \%)$ was higher, and also higher than in previously published work. It does not seem feasible that topical acyclovir could enhance the subsequent development of ocular complications, but this high frequency strongly suggests that topical acyclovir offers no therapeutic advantages when given early.

Table IV. Severity of pain

\begin{tabular}{|c|c|c|c|c|c|c|c|}
\hline & \multicolumn{7}{|c|}{ Median visual analogue score (interquartile range) } \\
\hline & Presentation & 1 week & 2 weeks & 1 month & 3 months & 6 months & 12 months \\
\hline $\begin{array}{l}\text { Ointment } \\
\text { Tablets }\end{array}$ & $\begin{array}{c}46.00 \\
(20.0-54.0) \\
34.0 \\
(10.75-54.75)\end{array}$ & $\begin{array}{c}44.75 \\
(7.25-64.25) \\
29.5 \\
(11.0-47.0)\end{array}$ & $\begin{array}{c}25.00 \\
(6-50.75) \\
17.0 \\
(0-43.0)\end{array}$ & $\begin{array}{c}16.00 \\
(0-50.25) \\
1.00 \\
(0-33.5)\end{array}$ & $\begin{array}{c}0.00 \\
(0-24.0) \\
0.0 \\
(0-0.75)\end{array}$ & $\begin{array}{c}0.00 \\
(0-20.25) \\
0.0 \\
(0-0)\end{array}$ & $\begin{array}{c}0.00 \\
(0-0) \\
0.0 \\
(0-0)\end{array}$ \\
\hline$p^{\mathrm{a}}$ & 0.63 & 0.21 & 0.17 & 0.13 & 0.20 & 0.08 & 0.45 \\
\hline
\end{tabular}

${ }^{a}$ Mann-Whitney $U$-test for significance. 
The role of topical acyclovir in preventing ocular complications merited study because of its higher penetration into the eye. Oral doses of $800 \mathrm{mg}$ acyclovir every 4 hours in volunteers produce mean steady-state peak and trough plasma levels of 7.5 and $4.5 \mu \mathrm{M}$ respectively. ${ }^{19}$ These values are in excess of the mean effective dose $\left(\mathrm{ED}_{50}\right)$ for most varicella zoster strains ( $\left.3-4 \mu \mathrm{M}^{20,21}\right)$ but not greatly so. In contrast, following slow intravenous infusion of $5 \mathrm{mg} / \mathrm{kg}$ of the drug every 8 hours much greater mean peak plasma levels of approximately $43 \mu \mathrm{M}$ were achieved. This probably accounts for the more significant clinical effect seen with the intravenous formulation. Poirier et $a .^{22}$ demonstrated mean aqueous levels of $7.5 \mu \mathrm{M}$ after 24 hours' administration of topical acyclovir, a concentration well above the $\mathrm{ED}_{50}$ of zoster strains, and so it seemed possible that topical acyclovir might achieve prophylactic effects in the eye similar to or greater than those seen with the oral drug.

Although numbers in this study are higher than in previous studies of acute $\mathrm{HZO},{ }^{13,14}$ the change in pattern of GP prescribing caused increasing difficulty with recruitment. This, together with the results of an interim analysis, led the authors to terminate recruitment. Successful marketing of oral acyclovir has been based on limited evidence of clinical benefit. Conflicting results have led to some criticism between authors from different centres concerning study design and statistical evaluation, ${ }^{13-15}$ making it difficult for ophthalmologists to decide whether to use the drug. Large multicentre prospective studies involving GPs in recruitment will be needed in the evaluation of the next generation of antivirals if these difficulties are not to be repeated.

The aim of prophylactic antiviral therapy in HZO is to limit replication in the earliest phase after viral reactivation and thereby reduce secondary perineuritis and perivasculitis. Evidence from studies of the ocular pathology of zoster indicates involvement of posterior nerves and blood vessels. ${ }^{8}$ It seems that the beneficial effects of oral acyclovir in reducing ocular complications and pain are due to an influence posteriorly in the eye and along the course of the trigeminal nerve. In spite of higher anterior segment levels our study has shown that topical acyclovir is significantly less effective than the oral formulation and this may be due to insufficient drug levels in the posterior segment. Indeed the frequencies of complications were similar to those in placebo groups in previous studies. A placebo-controlled study of topical acyclovir alone in early HZO would be unethical and so a definitive comparison is not possible. However, the evidence presented in this study sugggests that topical acyclovir has no prophylactic value in the management of early HZO and cannot be recommended for this use.
Key words: Acyclovir, Herpes zoster ophthalmicus, Ocular complications, Pain, Prevention.

\section{REFERENCES}

1. Hope-Simpson RE. Postherapetic neuralgia. J R Coll Gen Pract 1975;25:571-5.

2. Burgoon CF, Burgoon JS, Baldridge GD. The natural history of herpes zoster. JAMA 1957;164:265-9.

3. Edgerton AE. Herpes zoster ophthalmicus. Arch Ophthalmol 1945;93:40-153.

4. Harding SP, Lipton JR, Wells JCD. Natural history of herpes zoster ophthalmicus, predictors of postherpetic neuralgia and ocular involvement. Br J Ophthalmol 1986;71:353-8.

5. Scheie HG. Herpes zoster ophthalmicus. Trans Ophthalmol Soc UK 1970;90:899-937.

6. Leisegang TJ. Corneal complications from herpes zoster ophthalmicus. Ophthalmology 1985;92:316-24.

7. Womack LW, Leisegang TJ. Complications of herpes zoster ophthalmicus. Arch Ophthalmol 1983;101:42-5.

8. Marsh RJ, Cooper M. Ophthalmic herpes zoster. Eye 1993; 7:350-70.

9. Brown GR. Herpes zoster: correlation of age, sex distribution, neuralgia and associated disorders. South Med J 1976;69:576-8.

10. deMoragas JM, Kierland RR. The outcome of patients with herpes zoster ophthalmicus. Arch Dermatol 1957;75:193-6.

11. McGill J, Chapman C. A comparison of topical acyclovir with steroids in the treatment of herpes zoster keratouveitis. Br J Ophthalmol 1983;67:746-50.

12. Marsh RJ, Cooper M. Double-masked trial of topical acyclovir and steroids in the treatment of herpes zoster ocular inflammation. Br J Ophthalmol 1991;75:542-6.

13. Cobo LM, Foulks GN, Leisegang T, Lass J, Sutphin JE, Wilhelmus $\mathrm{K}$, et al. Oral acyclovir in the treatment of acute herpes zoster ophthalmicus. Ophthalmology 1986;93:763-70.

14. Harding SP, Porter SM. Oral acyclovir in herpes zoster ophthalmicus. Curr Eye Res 1991;10:177-82.

15. Aylward GW, Claoué CMP, Marsh RJ, Yasseem N. Influence of oral acyclovir on ocular complications of herpes zoster ophthalmicus. Eye 1994;8:70-4.

16. Huff JC, Bean B, Balfour HH, Laskin OL, Connor JD, Corey L, et al. Therapy of herpes zoster with oral acyclovir. Am J Med 1988;85 (Suppl 2A):84-9.

17. Morton P, Thomson AN. Oral acyclovir in the treatment of herpes zoster in general practice. N Z J Med 1989;102:93-5.

18. Wood MJ, Ogan PH, McKendrick MW, Care CD, McGill JI, Webb EM. Efficacy of oral acyclovir treatment of acute herpes zoster. Am J Med 1988;85:79-83.

19. Bridgen D, Fowle A, Rosling A. In: Collier L, Oxford J, editors. Developments in antiviral therapy. London: Academic Press, 1980:53-62.

20. Biron KK, Elion GB. In vitro susceptibility of varicella zoster virus to acyclovir. Antimicrob Agents Chemother 1980;18:443-7.

21. Crumpacker CS, Schnipper LE, Zaia JA, Levin HJ. Growth inhibition by acycloguanosine of herpesviruses isolated from human infections. Antimicrob Agents Chemother 1979;15:642-5.

22. Poirier RH, Kingham JD, de Miranda P, Annel M. Intraocular antiviral penetration. Arch Ophthalmol 1982;100: 1964-9. 